\title{
Burden of Fatigue among Adults Living with HIV/AIDS Attending Antiretroviral Therapy in EthiopiaBurden of Fatigue among Adults Living with HIV/AIDS Attending Antiretroviral Therapy in Ethiopia
}

Tsiwaye Gebreyesus ( $\square$ nadaeyoba@gmail.com )

Mekelle University https://orcid.org/0000-0003-3416-5463

\section{Addisalem Belay}

Mekelle University College of Health Sciences

Gebretsadik Berhe

Mekelle University College of Health Sciences

Gebremedhin Haile

Mekelle University College of Health Sciences

\section{Research article}

Keywords: Fatigue, HIV/AIDS, Associated factors, Prevalence, Ethiopia

Posted Date: November 21st, 2019

DOI: https://doi.org/10.21203/rs.2.17567/v1

License: (9) (1) This work is licensed under a Creative Commons Attribution 4.0 International License. Read Full License

Version of Record: A version of this preprint was published at BMC Infectious Diseases on April 15th, 2020. See the published version at https://doi.org/10.1186/s12879-020-05008-4. 


\section{Abstract}

Objectives: This study assessed the prevalence and determined factors associated with fatigue among adults living with HIV/AIDS attending antiretroviral therapy at health facilities of Mekelle city, Tigray, North Ethiopia, 2019.

Methods: Institution based cross-sectional study design was conducted among 609 HIV/AIDS patients who were selected by using a systematic random sampling method. Data were collected by using interviewer administered structured questionnaire. Level of fatigue was measured by fatigue severity scale.

Results: The prevalence of fatigue was found to be $51.7 \%$. The contributing factors that had statistically significant association with fatigue were: having children [AOR= 2.01; 95\% Cl: 1.09-3.71], CD4 count 200-499 cells/mm3 [AOR=2.81; 95\% Cl: 1.58-4.99], having anemia [AOR=4.90 95\% Cl: 2.40-9.97], having co-morbid health conditions [AOR $=3.65 ; 95 \% \mathrm{Cl}$ : 1.71-7.78], showing depression [AOR=3.68 95\% $\mathrm{Cl}$ : 1.99-6.79], not being physically active $[\mathrm{AOR}=3.2095 \% \mathrm{Cl}$ : $1.50-6.81]$, clinical stage II and IV $[\mathrm{AOR}=3.11 ; 95 \% \mathrm{Cl}: 1.51-6.40]$ and $[\mathrm{AOR}=$ 4.08; $95 \% \mathrm{Cl}: 1.37-12.14]$ respectively.

Conclusion: The prevalence of fatigue was medium compared to the global prevalence. Having children, having CD4 count 200-499 cells/mm3, being in clinical stage II/IV, being anemic, having co-morbid health conditions, showing depression, and not being physically active were positively associated with fatigue. Health care stakeholders need to give special attention for HIV patients with the identified associated factors. Keywords: Fatigue, HIV/AIDS, Associated factors, Prevalence, Ethiopia

\section{Background}

Human Immune Virus (HIV) is one of the prevalent chronic health condition, which attack body's immune system and interfere with abilities to fight infection [1]. In 2017, around 36.9 million people live with HIV (PLHIV) globally, and the vast majority (76\%) of victims were located in sub-Saharan Africa [1, 2]. Ethiopia is one of the those countries with estimated prevalence of 1.1\% [3]. Despite substantial regional variations in the prevalence, the prevalence of HIV/AIDS in Tigray regional state was $1.2 \%$ [4].

Even though highly active antiretroviral therapy (HAART) helped patients to live longer and healthier life, it accompanied with numerous challenges in terms of associated symptoms and treatment side effects [5-7]. From this symptoms, fatigue is one of the most frequently reported symptoms by HIV/AIDS patients [8, 9], which is defined as 'subjective sensations of weariness, increasing sense of effort, mismatch between effort expended and actual performance, or exhaustion which is not relived by additional sleep or rest' [10].

Fatigue is one of the most common and devastating HIV-related symptoms, with a varying prevalence in different studies. A systematic review of 42 international studies of developed countries, reported that the prevalence of fatigue among HIV/AIDS patients varied from $33 \%$ to $88 \%$ [11]. In Africa, evidences on the prevalence and related factors of HIV-related symptoms including fatigue remains unclear [8].

Even though the exact etiology of fatigue among HIV-infected patients remains unknown, previous studies reported various socio-demographic [12,13], disease and treatment related [14-16], psychosocial and personal factors [17-19] as associated factors for having fatigue. 
Having fatigue may have a broad impact on physical, emotional and cognitive function of HIV/AIDS patients, which may have various social, psychological and behavioral consequences [20,21]. These consequences adversely affect patients day-to-day activates and result in poor quality of life, which cause undesirable consequence on ART adherence [22].It also imposes an enormous burden on family and community by affecting patients' job desire and productivity level [20, 23, 24].

Fatigue interfere with activities of daily living, socialization, and mental function of patients [20, 21]. In the long run, patient may result in job loss and social isolation due to extended impact of fatigue on productivity and social duties [24]. On top of this, it may interfere with medication adherence, which can cause rising of viral load and other opportunistic infections [25]. Similarly, a study reported that, fatigue is one of the top reasons for poor medication adherence in East Africa [26]. Even though fatigue had such consequences, it had been underreported by patients and under-managed by health care providers in developing countries [27].

The prevalence of fatigue among HIV/AIDS patients differs across different studies. An analysis of evidence on fatigue among HIV/AIDS patients in 2013 reported that, the prevalence of fatigue in the analized articles was reported between $55 \%$ and $65 \%$ [28]. Fatigue had been reported by patients with HIV/AIDS as one of the most common HIV-related symptoms they experience in life [29-33].

Several factors such as socio demographic factors have been correlated to the development of fatigue among HIV/AIDs patients. The study in a sample of 372 HIV-positive patients reported that, from the total number of women participants, more than half (61.6\%) of them suffering from fatigue [29]. Similarly, the study in France reported that women reported higher scores of fatigue than man [34].

Studies also found out that, higher fatigue level was reported by HIV-infected patients who were single, unemployed, and under-weight $[12,28,36,37]$. Similarly, the finding of the study from USA showed that having inadequate income had an association with higher fatigue intensity [29]. Lower educational level and urban residence were significantly associated with fatigue in the study including $607 \mathrm{HIV} /$ AIDS patients in South Africa [9]. Like ways, another study identified that, lower educational level was associated with perceived fatigue level of HIV/AIDS patients [8].

Many studies revealed that there was a signficant relationship betewen longer duration since the first HIVdiagnosis and reported fatigue [14, 20,35]. In the contrary, there was no relationship between the presence of fatigue and time since first HIV-diagnosis, CD4 cell count, clinical stage of HIV, or use of antiretroviral medications [38].

Some studies showed that psychosocial and personal factors such as depression and psychiatric cases were found to be strong predictors of fatigue among PLHIV [11, 29, 33].

A longitudinal study in USA revealed that depression had a strong relationship with fatigue report [20]. In addition, severity of insomnia had been associated with greater fatigue, and depression may contribute to both insomnia and fatigue [39]. Being physically active has also been reported as a protective factor for having fatigue among HIV-positive patients [19, 36, 40].

Our extensive search revealed scarce published regional works reporting the prevalence and associated factors of fatigue remained unclear in the sub-Saharan region particularly in Ethiopia. Therefore, the aim of this study 
was to determine the prevalence and identify factors associated with fatigue among adults living with HIV/AIDS attending antiretroviral therapy at health facilities of Mekelle city, Tigray, North Ethiopia.

\section{Methods}

\section{Study area and period}

This study was conducted in public and private health facilities of Mekelle city, Tigray, North Ethiopia. Mekelle city is a capital city of Tigray regional state, located in North Ethiopia, at a distance of 780 kilometers from Addis Ababa, the capital city of Ethiopia. The city has seven local administrative (kifleketema) and One Hundred sub-districts (ketena). Mekelle zone has an estimated total population of 256,000 [41]. The health service system in Mekelle is consisting of both public and private health care centers. There are four public and two private hospitals. In addition there are nine health centers and 38 private clinics. The public hospitals are Mekelle hospital, Quiha hospital, Ayder referral hospital and Hewo hospital and the health centers are Mekelle, Semien, Kasech, Quiha, Serawat, Lachi, Aynalem, Adishendehun and Adiha. From these health facilities, all hospitals and 8 health centers provide ART service for the patients. According to the report of Tigray regional state health bureau, currently a total of 9662 adult ART users are accessing the service from 14 public and private health facilities in Mekelle city. An institutional based cross-sectional study was conducted from April $1-30,2019$.

\section{Population, sample size and sampling procedures}

The source population was all adults (Age $\geq 18$ ) living with HIV/AIDS who attended ART and who had been diagnosed with HIV/AIDS at least 30 days prior to enrollment to the study. HIV/AIDS patients having a diagnosed bipolar disorders, schizophrenia, or dementia, women with known pregnancy, and patients with chronic illness condition marked by fatigue such as renal disease, cancer, multiple sclerosis, or known cardiac patients were excluded from the study. The sample size was calculated by using single population proportion formula. Since there is no related study, the proportion of $50 \%$ was taken to have maximum sample size. This gives a sample of 369 and by considering 10\% non-response rate and 1.5 design effect, the final calculated sample size 609. According to Tigray health bureau report, at the end of 2018, the total adult ART cases in Mekelle city was found to be 9662 , with an estimated number of 3220 patient flow per month. A multistage sampling procedure was used to select study subjects and the total numbers of health facilities were selected by using a simple random sampling technique. Accordingly, 50\% of the health facilities, i.e. two public hospitals, one private hospital, and four health centers were selected. Then, the number of study units to be sampled from each facility was determined by using a proportional allocation and systematic random sampling was employed to select each study subjects. By using ART user card number the first participant was selected by simple random sampling technique and every $\mathrm{K}^{\text {th }}$ interval was followed until the allocated number of study subjects for each facility was reached. The sampling fraction $\left(\mathrm{K}^{\text {th }}\right)$ was stated as (the ART case load /sample size), every $5^{\text {th }}$ ART user was recruited for each health facilities.

\section{Variables}

Outcome variable: Fatigue 
Socio demographic factors: Gender, age, marital status, presence of children, educational status, occupation, residence, average monthly income, and body mass index (BMI)

Disease and treatment related factors: Recent CD4 counts, duration since HIV confirmed, current World Health Organization (WHO) classification of HIV clinical stage, current statues of anemia, current drug regimen and,currentco-morbid health conditions,.

Psychosocial and personal factors: Depressions, insomnia, Physical activity, presence of physical disability

\section{Measurement of variables}

Burden is defined as the prevalence of fatigue. By using the fatigue severity scale average score, a patient who scored greater than or equal to four was considered as having clinically significant fatigue [42].A patient was considered as physically active if the total minutes reported by participants for mentioned activates add up and it was greater than 150 minutes per week [19].Co-morbid health conditions was defined as the presence of one or more additional confirmed diseases or disorders co-occurring with HIV/AIDS (Hypertension, Epilepsy, opportunistic infections including tuberculosis) currently [43].A participant was considered as physically disableup onself-report of the presence or absence of physical disability that have significant negative impacts on one or more major activities of daily living.Participants who scored $\geq 5$ on 'patient's health questioner-9' were considered as having for depression. Participants whose score was $>7$ on 'insomnia severity scale' were considered to have insomnia. Body mass index is the ratio of weight to height in meters squared, less than 18.5 being underweight, 18.5-24.9 normal weight, 25-29.9 overweight, and >30 obesity.

\section{Data Collection tool and procedures}

The tool was adopted from fatigue severity scale (FSS) for measuring fatigue intensity, and insomnia severalty index for measuring insomnia. Interviewer administered structured questionnaire was used which included interview questionnaire (for sex, age, marital status, presence of children, educational status, occupation, residence, income, insomnia, depression, physical activities and, fatigue), measurements (for height and weight) and data abstraction format ( for recent CD4 counts, duration since HIV-confirmed, current WHO classification of HIV clinical stage, current anemia statues, current drug regimen and,current co-morbid health conditions) used to collect data from patients medical record. Depression was measured by using patient's health questioner-9, and there is some modification in question number 9. Question number 9 'Thoughts that you would be better off dead or of hurting yourself in some way' modified in to 'Thoughts of hurting yourself in some way, if yes, how far' than according to their response they were asked to grade it. Data were collected by seven bachelor of science degree nurses with face to face interviewing technique and the data collection was supervised by two physiotherapists. Study participants who had severe fatigue were advised to visit physiotherapy department as soon as possible.

\section{Data quality control}


In order to maintain the quality of data all the essential measures were done before, during and after the data collection. The questioner was translated to local language (Tigrigna) then translated back to English to ensure its consistency. All data collectors and supervisors were trained for one day on the purpose of the study, details of the data collection tool, interviewing techniques, and importance of privacy and ensuring confidentiality of the respondents prior to the actual data collection. The questionnaire was pre-tested on $5 \%$ (31) of the total sample size among the ART users in Wukro general hospital which is 45 kilometers far away from the study area before a week of the actual data collection period. Based on the findings of the pre-test the necessary changes were made which included the omission of viral load from the questioner because this laboratory test was not taken anymore. Beside, some modifications have been made in language clarity in the scales of insomnia and depression. The supervisors made routine checkups for completeness and consistency of the data. The questionnaire was reviewed and checked for completeness, accuracy and consistency by the supervisors and investigators to take timely corrective measures. The data were coded and stored in a proper area and kept confidential.

\section{Statistical analysis}

Data were cleaned and entered into Epi Info version 7 and exported to SPSS version 23 software for further process and analysis. Descriptive statistics was presented in the form of frequency, percentage, mean, median, range and standard deviation. Chi-square assumption was checked for all categorical predictor variables. Binary logistic regression model was fitted to identify factors that were significantly associated with the outcome (fatigue). Variables having P-value $<0.25$ in the bivariate logistic regression analyses, were considered as potential candidates in the final multivariable logistic regression analysis. P-value $<0.05$ was used to declare statistical significance in the multivariable model. Multi-collinearity was checked using Variance Inflation Factor (VIF) and the overall goodness of fit of the model was checked using Hosmer-Lemeshow goodness of fit test. Finally, the adjusted odds ratio (AOR) with its $95 \%$ confidence interval (Cl) was considered as statically significant.

\section{Results}

\section{Descriptive statistics}

\section{Socio-demographic characteristics of adults living with HIV/AIDS}

Among the total 609 study participants, a total of 567 participants participated in this study, giving the response rate of $93.1 \%$. From participates, 327 (57.7\%) were females with the mean age of $38 \pm 10.79$ years. Nearly half $258(45.5 \%)$ of the participants were married and 157 (27.7\%) of them have children. Regarding residence, 455 $(80.2 \%)$ of participates where from urban area with median monthly household income of 1500 . One hundred seventy two (30.3\%) of participants completed primary education and about $270(47.6 \%)$ of the respondents had healthy BMI score. (Table: 1 )

\section{Disease and treatment related characteristics of people living with HIV/AIDS}


More than half 308 (54.3\%) of participants recent CD4 count was between $200-499$ cells $/ \mathrm{mm} 3$. Regarding with clinical stage, more than half of the participants $316(55.7 \%)$ was on clinical stage I and $136(24.0 \%)$ of participants were anemic. (Table: 2)

\section{Psychosocial and personal characteristics of adult people living with HIV/AIDS}

From the total respondents almost half of the participants, 284 (50.1\%) reported clinically significant depression and 255 (45.0\%) suffered from insomnia. (Table: 3 )

\section{Prevalence of fatigue among adult HIV/AIDS patients}

Out of 567 study participants, 293 (51.7\%): 95\% Cl [47.4, 55.7] were found to be fatigue. In this study the prevalence of fatigue was relatively higher in male participants $132(55 \%)$ and patients who were widowed 55 $(67.1 \%)$, and unemployed $39(75.0 \%)$. The development of fatigue was relatively higher among anemic study participant 119 (87.5\%), those participants with CD4 count > 20067 (73.6\%), who were depressed 226 (79.6\%), and those participants who had physical disability 11 (84.6) than other groups. (Table: 4)

\section{Factors associated with fatigue among people living with HIV/AIDS}

Variables with $p$-value of $<0.25$ entered to multivariable logistic regression analysis were: sex, age, marital status, presence of children, occupation, residence, average monthly income, BMI, CD4 counts, total duration since HIV confirmed, clinical stage, anemia, drug regimen, co-morbid health conditions, depressions, insomnia, Physical activity, and Presence of physical disability.

In the multivariable logistic regression analysis, factors which include presence of children, CD4 cell count, current anemia status of the patients, and current WHO classification of HIV diseases, depression level, and current co-morbid health conditions were found to be significantly associated with fatigue at $5 \%$ level of significance.

\section{Discussion}

This study mainly investigated the prevalence and associated factors of fatigue among HIV patients attending ART in public and private health facilities of Mekelle city. Having children, CD4 cell count 200-499, being anemic, being in II/IV WHO classification of HIV stage, showing depression, presence of co-morbid health conditions, and physical activities were significantly associated with being fatigue.

In the current study the prevalence of fatigue was found to be $51.7 \%$ : $95 \% \mathrm{Cl}[47.4,55.7]$. This result is relatively comparable with the finding of study done in South Africa,55\% [8], and USA,54\% [38]. This consistent result can be explained by the use of large sample size, similarities in study population and similarities in eligibility criteria. 
On the other hand the prevalence in our study was lower than the finding of the studies done in South Africa, $66.7 \%$ [9], UK, 65.1\% [17], Uganda (61\%) [44], and china, 86.8\% [31]. This observed difference could be due to difference in populations, for example, the study in South Africa use study-subjects who were extremely ill and the other two studies (Uganda and UK) used participants who develop at least two HIV-related symptoms, which may increase the prevalence of fatigue. The other possible reason can be the difference in assessment tool, for example, the study from South Africa used the revised sign and symptom checklist for persons with HIV disease, the study from UK used Chalder Fatigue Scale and, short form of memorial symptom assessment Scale used in study from Uganda. The first two studies reported the prevalence of fatigue, whereas this study reported clinically significant fatigue level (FSS $>4$ ). Difference in data collection and sampling method also can be another possible cause for the observed discrepancy, the study done in South Africa used convenience sampling, and the study done in china use case report forms that had been used for previous project. The study from UK used self-administered questioner that the investigators do not have information on those patients who failed to fill the questionnaire, but there is possibility that fatigued patients were more likely to participate, which may lead to over reporting the prevalence of fatigue.

Moreover, the finding of the our study is relatively higher than that of the study done in UK, which reported the prevalence of fatigue to be $28 \%$ [45]. This could be due to reason that the study done in the UK considered only severe fatigue reports to categorize as positive for fatigue, but the current study considered both moderate and severe, which may lower the prevalence of fatigue in the UK study. The other possible explanation for the discrepancy could be the use of different measurement tool and difference in population in which the samples were drawn.

In the current study participants who had children were 2 times more likely to develop fatigue when compared to those who had not children. Similar association was found from studies done in South Africa, USA, and French $[8,29,34]$ which reported that patients who had children had a higher risk of developing fatigue. This result may be attributed to the additional work load and responsibilities that came up with having children in terms of financial and social burdens.

In the present study, participants whose current CD4 count ranged from 200-499 had approximately three times higher risk for developing fatigue compared to those whose CD4 count was $>500$. In the other hand, a study done in USA revealed that patients who had CD4 count $>200$ had a high risk of developing fatigue [16]. The observed discrepancy might be due to high number $(50.3 \%)$ of the current study participants were in this range (CD4 count 200-499). Another possible reason could be those patients with low CD4 count may have additional opportunistic infections which might have contributed for being fatigued. This finding is in line with the other finding of our study in which the current WHO classification of HIV/AIDS stage II and IV was significantly associated with reported fatigue when compared with stage I, which supported by the study done in French [34]. This can be due to the reduction of CD 4 count and presence of opportunistic infections in later stages of HIV/AIDS when patients may have additional contribution for their fatigue intensity.

This study revealed that HIV-patients who had other co-morbid health condition were four times more likely to develop fatigue than those who do not had that additional diagnosis. This finding is consistent with the finding of study done in USA [44]. This could be due to the double burden of symptoms of HIV and other co-occurred health conditions which can cause fatigue by them-selves. 
In the current study, participants who didn't perform mild to moderate physical exercise in regular bases had approximately four times higher risk of developing fatigue than those who were not engaged in physical activates. Similarly, the study done in French reported that being physically active was significantly associated with reduced perceived physical fatigue [34]. The possible relationship might be due to the positive impact of physical exercise on the quality of life of HIV-positive patients in reducing acute fatigue, muscular weakness or pain that they experience. Moreover, physical activities could have positive effects on mood, which is believed to increase a positive influence on the reduction of perceived fatigue [46].

The finding of the present study indicated that, patients with depression were about four times more likely to be fatigue as compared with those patients with no depression; this finding also can be related to many previous studies. The study done in the USA reported that depressed participants had about two times a risk of experiencing fatigue [23]. Similarly, studies from the same country reported that depression was significantly associated with HIV-related fatigue [14,35]. Even though it is difficult to predict cause and effect relationship, this might be seen in both turns, depression may lead to fatigue, and in turn the inability to carry out normal activities due to fatigue or having HIV/AIDS by itself may lead to depression.

In our study, participants who had anemia had approximately five times higher risk for developing fatigue than those whose had no anemia which is in line with the studies done in USA [38] and China [31]. The possible explanation could be certain diseases including HIV can cause the reduction in red blood cell below a normal level so that the body tries to compensate in a number of ways which include redistribution of blood in order to give more oxygen to critical organs such as brain by reducing from other body parts, which may result in fatigue.

\section{Limitation of the study}

Limitation of this study includes the lack of information about the use of antidepressant and sleeping pills, which could have influenced the scores of 'Patients health questioner-9' and 'insomnia severity scale'. Moreover, as most of the previous researches were done in the developed countries, it was difficult to compare the result of this study with other studies and the use of secondary source can be mentioned as limitation of this study. Hence, further longitudinal studies in the area are needed to be conducted.

\section{Conclusion}

The prevalence of fatigue among adult PLHIV was medium compared with global prevalence. Having children, having CD4 count 200-499 cells/mm3, being in Clinical Stage II or IV, being anemic, having co-morbid health conditions, having depression, and not being physical active were statistically associated with fatigue.

\section{Declarations}

\section{Ethics approval and consent to participate}

Ethical clearance was obtained from Health Research Ethics Review Committee MU/CHS. Informed consent was obtained from the study participants after being informed in detail about the objective, purpose, benefits and risks of the study. Appropriate measures were taken to assure confidentiality of information both during and after data collection. 
Consent for publication

This section is not applicable.

Availability of data and material

Additional data could be obtained from the corresponding author upon formal request.

Declaration of Interest

The authors declare that they have no conflict of interest.

\section{Funding}

This work was fully funded by college of health sciences, Mekelle University. The funder has no role in the design of the study, data collection, and analysis, interpretation of data and in writing the manuscript.

\section{Authorship}

All authors contributed to the conception and design of the study, acquisition, analysis and interpretation of data, drafting the article or revising it critically for important intellectual content, and final approval of the version to be submitted.

\section{Acknowledgements}

We are thankful to Mekelle University, college of health sciences for funding the project. We would like to express our special gratitude to all study participants for sparing their time during data collection.

\section{References}

1.HIV/AIDS, J. U. N. P.o., UNAIDS data 2017. Geneva: Switzerland: UNAIDS 2017, 2018.

2.Unaids, J., Fact sheet-latest global and regional statistics on the status of the AIDS epidemic. Geneva: UNAIDS, 2017.

3.Girum, T., A. Wasie, and A. Worku, Trend of HIV/AIDS for the last 26 years and predicting achievement of the 90-90-90 HIV prevention targets by 2020 in Ethiopia: a time series analysis. BMC infectious diseases, 2018. 18(1): p. 320.

4.Lakew, Y., S. Benedict, and D. Haile, Social determinants of HIV infection, hotspot areas and subpopulation groups in Ethiopia: evidence from the National Demographic and Health Survey in 2011. BMJ open, 2015. 5(11): p. e008669.

5.Wu, J., et al., Self-reported sleep disturbances in HIV-infected people: a meta-analysis of prevalence and moderators. Sleep medicine, 2015. 16(8): p. 901-907.

6.Bernard, C., F. Dabis, and N. de Rekeneire, Prevalence and factors associated with depression in people living with HIV in sub-Saharan Africa: A systematic review and meta-analysis. PloS one, 2017. 12(8): p. e0181960. 
7.Biraguma, J., E. Mutimura, and J. M. Frantz, Health-related quality of life and associated factors in adults living with HIV in Rwanda. SAHARA-J: Journal of Social Aspects of HIV/AIDS, 2018. 15(1): p. 110-120.

8.Voss, J. G., et al., Symptom burden of fatigue in men and women living with HIV/AIDS in Southern Africa. Journal of the Association of Nurses in AIDS Care, 2007. 18(4): p. 22-31.

9.Peltzer, K. and N. Phaswana-Mafuya, The symptom experience of people living with HIV and AIDS in the Eastern Cape, South Africa. BMC health services research, 2008. 8(1): p. 271.

10.Kluger, B. M., Krupp, L. B., \& Enoka, R. M, Fatigue and fatigability in neurologic illnesses: proposal for a unified taxonomy. Neurology, 2013. 80(4), 409-416.

11.Jong, E., et al., Predictors and treatment strategies of HIV-related fatigue in the combined antiretroviral therapy era. Aids, 2010. 24(10): p. 1387-1405.

12.Phillips, K. D., et al., Physiological and psychological correlates of fatigue in HIV disease. Biological Research for Nursing, 2004. 6(1): p. 59-74.

13.Evans, W. J. and C. P. Lambert, Physiological basis of fatigue. American Journal of Physical Medicine \& Rehabilitation, 2007. 86(1): p. S29-S46.

14.Barroso, J., J. R. Carlson, and J. Meynell, Physiological and psychological markers associated with HIVrelated fatigue. Clinical nursing research, 2003. 12(1): p. 49-68.

15.Barroso, J., et al., Physiological and psychosocial factors that predict HIV-related fatigue. AIDS and Behavior, 2010. 14(6): p. 1415-1427.

16.Sullivan, P. S., M. S. Dworkin, and A. S.o.H. D. Investigators, Prevalence and correlates of fatigue among persons with HIV infection. Journal of pain and symptom management, 2003. 25(4): p. 329-333.

17.Henderson, M., et al., Fatigue among HIV-infected patients in the era of highly active antiretroviral therapy. HIV medicine, 2005. 6(5): p. 347-352.

18.Salahuddin, N., et al., Daytime sleepiness, nighttime sleep quality, stressful life events, and HIV-related fatigue. Journal of the Association of Nurses in AIDS Care, 2009. 20(1): p. 6-13.

19.Webel, A. R., et al., Physical activity is associated with reduced fatigue in adults living with HIV/AIDS. Journal of advanced nursing, 2016. 72(12): p. 3104-3112.

20.Barroso, J., et al., Fatigue in HIV-infected people: a three-year observational study. Journal of pain and symptom management, 2015. 50(1): p. 69-79.

21.Barroso, J., et al., Intensity, chronicity, circumstances, and consequences of HIV-related fatigue: a longitudinal study. Clinical nursing research, 2014. 23(5): p. 514-528.

22.George Dalmida, S., et al., Depressive symptoms and fatigue as mediators of relationship between poor sleep factors and medication adherence in HIV-positive women. Journal of Research in Nursing, 2015. 20(6): p. 
499-514.

23.Pence, B. W., et al., Chronicity and remission of fatigue in patients with established HIV infection. AIDS patient care and STDs, 2009. 23(4): p. 239-244.

24.Wagener, M., et al., Employment-related concerns of HIV-positive people in the Netherlands: input for a multidisciplinary guideline. Journal of occupational rehabilitation, 2014. 24(4): p. 790-797.

25.Safiya George Dalmida, M. M. H., Rodney Fox,Augustina Mara Delaney, Depressive symptoms and fatigue as mediators of relationship between poor sleep factors and medication adherence in HIV-positive women. Research in Nursing, 2015. 20(6) 499-514

26.Camlin et al., C.e., Patient-reported factors associated with reengagement among HIV-infected patients disengaged from care in East Africa. HHS Public Access 2016. 28; 30(3): 495-502..

27.P Jenkin et al., P. J.e., The experience of fatigue for adults living with HIV. Journal of Clinical Nursing 2006. 15: p. $1123-1131$.

28.Barroso, J. and J. G. Voss, Fatigue in HIV and AIDS: an analysis of evidence. Journal of the Association of Nurses in AIDS Care, 2013. 24(1): p. S5-S14.

29.Voss, J. G., Predictors and correlates of fatigue in HIV/AIDS. Journal of pain and symptom management, 2005. 29(2): p. 173-184.

30.DiBonaventura, M.d., et al., The association of HIV/AIDS treatment side effects with health status, work productivity, and resource use. AIDS care, 2012. 24(6): p. 744-755.

31.ZhibinLiu, J., HuijuanLiu,YantaoJin Factors associated with fatigue in acquired immunodeficiency syndrome patients with antiretroviral drug adverse reactions: a retrospectivestudy. journal of traditional Chinese medicine 2013. 33(3).

32.Langseth, R., Prevalence and predictors of fatigue among people living with HIV in Northern and Southern Norway 2018.

33.Paddison, J., et al., Fatigue in psychiatric HIV patients: a pilot study of psychological correlates.

Psychosomatics, 2009. 50(5): p. 455-460.

34.Bergamaschi, A., et al., Perceived HIV-related physical fatigue, sociodemographic characteristics and physical activity: A cross-sectional study. Journal of clinical nursing, 2019.

35.Meynell, J. and J. Barroso, Bioimpedance analysis and HIV-related fatigue. Journal of the Association of Nurses in AIDS Care, 2005. 16(2): p. 13-22.

36.Payne, C., Whiffen, P. J., \& Martin, S., Interventions for fatigue and weight loss in adults with advanced progressive illness. Cochrane Database of Systematic Reviews, 2012. 1. 
37.al, H.e., Demographic and IIIness-Related Variables Associated with HIVRelated Fatigue. NIH Public Access 2009. 19 (2): p. 90-97.

38.Breitbart, W., et al., Fatigue in ambulatory AIDS patients. Journal of pain and symptom management, 1998. 15(3): p. 159-167.

39.Low, Y., et al., The association of fatigue with depression and insomnia in HIV-seropositive patients: a pilot study. Sleep, 2011. 34(12): p. 1723-1726.

40.McMillan, E. M. and I. J. Newhouse, Exercise is an effective treatment modality for reducing cancer-related fatigue and improving physical capacity in cancer patients and survivors: a meta-analysis. Applied physiology, nutrition, and metabolism, 2011. 36(6): p. 892-903.

41.bālaśeltān, E. Y.s. and O. Macro, Ethiopia Demographic and Health Survey, 2005. 2006: Central Statistical Authority.

42.Valko, P. O., et al., Validation of the fatigue severity scale in a Swiss cohort. Sleep, 2008. 31(11): p. 16011607.

43.Goswami et al, G.e., Sleep Apnea Symptoms as a Predictor of Fatigue in an Urban HIV Clinic. AIDS PATIENT CARE and STDs, 2015. 29.

44.Wakeham, K., et al., Symptom burden in HIV-infected adults at time of HIV diagnosis in rural Uganda. Journal of palliative medicine, 2010. 13(4): p. 375-380.

45.Payne, B., et al., HIV-associated fatigue in the era of highly active antiretroviral therapy: novel biological mechanisms? HIV medicine, 2013. 14(4): p. 247-251.

46.Nosrat, S., J. W. Whitworth, and J. T. Ciccolo, Exercise and mental health of people living with HIV: A systematic review. Chronic illness, 2017. 13(4): p. 299-319.

\section{Tables}

Table 1: Socio-demographic characteristics of people living with HIV/AIDS attending ART, in Mekelle city public and private health facilities, Tigray, North Ethiopia, April 2019, (n=567). 


\begin{tabular}{|c|c|c|}
\hline Variables & Frequency & $\%$ \\
\hline \multicolumn{3}{|l|}{ Age group } \\
\hline $18-24$ & 44 & 7.8 \\
\hline $25-29$ & 69 & 12.2 \\
\hline $30-49$ & 354 & 62.4 \\
\hline$>=50$ & 100 & 17.6 \\
\hline \multicolumn{3}{|l|}{ Marital status } \\
\hline Single & 108 & 19.0 \\
\hline Married & 258 & 45.5 \\
\hline Divorced & 119 & 21.0 \\
\hline Widowed & 82 & 14.5 \\
\hline \multicolumn{3}{|l|}{ Body mass index(BMI) } \\
\hline Under weight & 187 & 33.0 \\
\hline Normal & 270 & 47.6 \\
\hline Over weight & 103 & 18.2 \\
\hline Obesity & 7 & 1.2 \\
\hline \multicolumn{3}{|l|}{ Occupation } \\
\hline House wife & 125 & 22.0 \\
\hline Unemployed & 52 & 9.3 \\
\hline Merchant & 106 & 18.7 \\
\hline Daily laborer & 121 & 21.3 \\
\hline Governmental/NGO Employed & 134 & 23.6 \\
\hline Others (farmer and student) & 29 & 5.1 \\
\hline
\end{tabular}

Table 2: Disease and treatment related characteristics of people living with HIV/AIDS attending ART, in Mekelle city public and private health facilities, Tigray, North Ethiopia, April 2019, (n=567). 


\begin{tabular}{lcl}
\hline Variables & Frequency & $\%$ \\
\hline CD4 counts & & \\
$<200$ cells/mm3 & 91 & 16.0 \\
200-499 cells/mm3 & 308 & 54.4 \\
$>=500$ cells/mm3 & 168 & 29.6 \\
WHO classification of HIV stage & \\
Stage I & 316 & 55.7 \\
Stage II & 103 & 18.2 \\
Stage III & 92 & 16.2 \\
Stage IV & 56 & 9.9 \\
Drug regimen & & \\
AZT+3TC+NVP & 115 & 20.3 \\
AZT+3TC+EFV & 41 & 7.2 \\
TD3+3TC+EFV & 257 & 45.3 \\
TDF+3TC+NVP & 121 & 21.4 \\
ABC+DDI+LPV/R & 33 & 5.8 \\
Co-morbid health conditions & \\
No & 438 & 77.2 \\
Yes & 129 & 22.8 \\
Duration since HIV confirmed & \\
0 - 35 months & 235 & 41.4 \\
$\geq 36$ & 332 & 58.6 \\
\hline
\end{tabular}

Table 3: Psychosocial and personal factors of people living with HIV/AIDS attending ART, in Mekelle city public and private health facilities, Tigray, North Ethiopia, April 2019, $(\mathrm{n}=567)$.

\begin{tabular}{lcc}
\hline Variables & Frequency & $\%$ \\
\hline $\begin{array}{l}\text { Depression } \\
\text { No }\end{array}$ & 283 & 49.9 \\
Yes & 284 & 50.1 \\
Insomnia & & \\
No & 312 & 55.0 \\
Yes & 255 & 45.0 \\
Level of physical activity & \\
No & 482 & 85.0 \\
Yes & 85 & 15.0 \\
Physical disability & \\
No & 554 & 97.7 \\
Yes & 13 & 2.3 \\
\hline
\end{tabular}


Table 4: prevalence of fatigue among adults living with HIV/AIDS attending ART, in Mekelle city public and private health facilities, Tigray, North Ethiopia, April 2019, (n=567). 
No Yes

Frequency (\%)Frequency (\%)

\begin{tabular}{|c|c|c|c|}
\hline \multirow[t]{2}{*}{ Sex } & Male & $108(45.0)$ & $132(55.0)$ \\
\hline & Female & $166(50.8)$ & $161(49.2)$ \\
\hline \multirow[t]{4}{*}{ Age } & $18-24$ & $17(38.6)$ & $27(61.4)$ \\
\hline & $25-29$ & $31(44.9)$ & $38(55.1)$ \\
\hline & $30-49$ & $184(52.0)$ & $170(48.0)$ \\
\hline & $>=50$ & $42(42.0)$ & $58(58.0)$ \\
\hline \multirow[t]{4}{*}{ Marital statues } & Single & $40(37.0)$ & $68(63.0)$ \\
\hline & Married & $163(63.2)$ & $95(36.8)$ \\
\hline & Separated & $44(37.0)$ & $75(63.0)$ \\
\hline & Widowed & $27(32.9)$ & $55(67.1)$ \\
\hline \multirow[t]{6}{*}{ Occupation } & House wife & $68(54.4)$ & $57(45.6)$ \\
\hline & Unemployed & $13(25.0)$ & $39(75.0)$ \\
\hline & Merchant & $52(49.1)$ & $54(50.9)$ \\
\hline & Daily laborer & $62(51.2)$ & $59(48.8)$ \\
\hline & \multicolumn{2}{|c|}{ Governmental/NGO Employed68 (50.7) } & $66(49.3)$ \\
\hline & Others (farmer and student) & $11(37.9)$ & $18(62.1)$ \\
\hline \multirow[t]{4}{*}{ Level of education } & No education & $66(45.5)$ & $79(54.5)$ \\
\hline & Primary school & $84(48.8)$ & $88(51.2)$ \\
\hline & Secondary school & $64(47.1)$ & $72(52.9)$ \\
\hline & More than Secondary & $60(52.6)$ & $54(47.4)$ \\
\hline \multirow[t]{2}{*}{ Residence } & Urban & $234(51.4)$ & $221(48.6)$ \\
\hline & Rural & $40(35.7)$ & $72(64.3)$ \\
\hline \multirow[t]{2}{*}{ Presence of children } & No & $213(52.0)$ & $197(48.0)$ \\
\hline & Yes & $61(38.9)$ & $96(61.1)$ \\
\hline \multirow[t]{3}{*}{ BMI } & Under weight & $82(43.9)$ & $105(56.1)$ \\
\hline & Normal weight & $135(50.0)$ & $135(50.0)$ \\
\hline & Over weight and obesity & $57(51.8)$ & $53(48.2)$ \\
\hline
\end{tabular}




\begin{tabular}{|c|c|c|c|}
\hline \multirow[t]{3}{*}{ CD4 count } & $<200$ & $24(26.4)$ & 67 (73.6) \\
\hline & $200-499$ & $117(38.0)$ & 191(62.0) \\
\hline & $>=500$ & $133(79.2)$ & $35(20.8)$ \\
\hline \multicolumn{2}{|c|}{ WHO classification of HIV diseaseStage I } & $222(48.3)$ & $94(51.7)$ \\
\hline & Stage II & $26(25.2)$ & $77(74.8)$ \\
\hline & Stage III & $18(19.6)$ & $74(80.4)$ \\
\hline & Stage IV & $8(14.3)$ & $48(85.7)$ \\
\hline \multirow[t]{2}{*}{ Anemia status of the patient } & No & $257(59.6)$ & $174(40.4)$ \\
\hline & Yes & $17(12.5)$ & $119(87.5)$ \\
\hline \multirow[t]{5}{*}{ Drug regimen } & $\mathrm{AZT}+3 \mathrm{TC}+\mathrm{NVP}$ & $64(55.7)$ & $51(44.3)$ \\
\hline & $\mathrm{AZT}+3 \mathrm{TC}+\mathrm{EFV}$ & $24(58.5)$ & $17(41.5)$ \\
\hline & TD3+3TC+EFV & $131(51.0)$ & $126(49.0)$ \\
\hline & $\mathrm{TDF}+3 \mathrm{TC}+\mathrm{NVP}$ & $36(29.8)$ & $85(70.2)$ \\
\hline & $\mathrm{ABC}+\mathrm{DDI}+\mathrm{LPV} / \mathrm{R}$ & $19(57.6)$ & $14(42.4)$ \\
\hline \multirow[t]{2}{*}{ Co-morbid health conditions } & No & $256(58.4)$ & $182(41.6)$ \\
\hline & Yes & $18(14.0)$ & $111(86.0)$ \\
\hline \multicolumn{4}{|l|}{ Duration since HIV confirmed } \\
\hline & 0 - 35 months & $87(37.0)$ & $148(63.0)$ \\
\hline & $\geq 36$ & $187(56.3)$ & $145(43.7)$ \\
\hline \multicolumn{4}{|c|}{ Psychosocial and personal factors } \\
\hline \multirow[t]{2}{*}{ Depression } & No & $216(76.3)$ & $67(23.7)$ \\
\hline & Yes & $58(20.4)$ & $226(79.6)$ \\
\hline \multirow[t]{2}{*}{ Insomnia } & No & $213(68.3)$ & 99 (31.7) \\
\hline & Yes & $61(23.9)$ & $194(76.1)$ \\
\hline \multirow[t]{2}{*}{ Physical exercise } & No & $211(43.8)$ & $271(56.2)$ \\
\hline & Yes & $63(74.1)$ & $22(25.9)$ \\
\hline \multicolumn{2}{|c|}{ Presence of any physical disabilityNo } & $272(49.1)$ & $282(50.9)$ \\
\hline & Yes & $2(15.4)$ & 11 (84.6) \\
\hline
\end{tabular}


Table 5: Factors associated with fatigue among adults living with HIV/AIDS attending ART, in Mekelle city public and private health facilities, Tigray, North Ethiopia, April 2019, $(n=567)$. 
Presence of fatigue

$\begin{array}{llllll}\text { Yes } & \text { No } & \begin{array}{l}\text { Crude odds } \\ \text { ratio (COR) }\end{array} & \text { P-V } & \text { P-V } & \text { AOR(95\%CI) } \\ \text { Frequency } & \text { Frequency } & (95 \% \mathrm{CI})] & & \\ (\%) & (\%) & & \end{array}$

\begin{tabular}{|c|c|c|c|c|c|c|}
\hline \multicolumn{7}{|c|}{$\begin{array}{l}\text { Presence of } \\
\text { children }\end{array}$} \\
\hline Yes & $96(61.1 \%)$ & $61(38.9 \%)$ & $\begin{array}{l}1.70(1.17- \\
2.47)\end{array}$ & $\begin{array}{l}<.005^{*} \\
0.04\end{array}$ & $0.025^{* *}$ & $2.01(1.09-3.71) * *$ \\
\hline No & $197(48.0 \%)$ & $213(52.0 \%)$ & 1.000 & & & \\
\hline \multicolumn{7}{|c|}{ CD4 count } \\
\hline$<200$ & $67(73.6 \%)$ & $24(26.4 \%)$ & $\begin{array}{l}10.608(5.841- \\
19.266)\end{array}$ & $\begin{array}{l}< \\
0.001 *\end{array}$ & 0.09 & $2.14(0.89-5.10)$ \\
\hline $200-499$ & $191(62.0 \%)$ & $117(38.0 \%)$ & $\begin{array}{l}\text { 6.203(4.004- } \\
9.610)\end{array}$ & $\begin{array}{l}< \\
0.001 *\end{array}$ & $<0.001 * *$ & $2.81(1.58-4.99) * *$ \\
\hline$>=500$ & $35(20.8 \%)$ & $133(79.2 \%)$ & 1.000 & & & \\
\hline \multicolumn{7}{|c|}{$\begin{array}{l}\text { WHO classification } \\
\text { of HIV disease }\end{array}$} \\
\hline stage I & $94(29.7 \%)$ & $222(70.3 \%$ & 1.000 & & & \\
\hline Stage II & 77(74.8\%) & $26(25.2 \%)$ & $\begin{array}{l}\text { 6.994(4.218- } \\
11.598)\end{array}$ & $\begin{array}{l}< \\
0.001 *\end{array}$ & $0.002 * *$ & $3.11(1.51-6.40) * *$ \\
\hline Stage III & $74(80.4 \%)$ & 18(19.6\%) & $\begin{array}{l}9.709(0.207- \\
1.179)\end{array}$ & $\begin{array}{l}< \\
0.001 *\end{array}$ & 0.063 & $2.13(0.96-4.76)$ \\
\hline Stage IV & $48(85.7 \%)$ & $8(14.3 \%)$ & $\begin{array}{l}14.170(6.454- \\
31.110)\end{array}$ & $\begin{array}{l}< \\
0.001 *\end{array}$ & $0.011^{*}$ & $4.08(1.37-12.14) * *$ \\
\hline \multicolumn{7}{|c|}{$\begin{array}{l}\text { Anemia status of } \\
\text { the patient }\end{array}$} \\
\hline Yes & $119(87.5 \%)$ & $17(12.5 \%)$ & $\begin{array}{l}10.339(6.005- \\
17.802)\end{array}$ & $\begin{array}{l}< \\
0.001 *\end{array}$ & $<0.001 * *$ & $4.90(2.40-9.97) * *$ \\
\hline No & $174(40.4 \%)$ & $257(59.6 \%)$ & 1.000 & & & \\
\hline \multicolumn{7}{|c|}{ Co-morbid health conditions } \\
\hline Yes & $111(86.0 \%)$ & $18(14.0 \%)$ & $\begin{array}{l}8.674(5.090- \\
14.781)\end{array}$ & $<0.001 *$ & $0.001 * *$ & $\begin{array}{l}3.65(1.71- \\
7.78) * *\end{array}$ \\
\hline No & $182(41.6 \%)$ & $256(58.4 \%)$ & 1.000 & & & \\
\hline \multicolumn{7}{|c|}{ Depression } \\
\hline Yes & $226(79.6 \%)$ & $58(20.4 \%)$ & $\begin{array}{l}12.562(8.438- \\
18.702)\end{array}$ & $\begin{array}{l}< \\
0.001 *\end{array}$ & $\begin{array}{l}< \\
0.001 * *\end{array}$ & $3.68(1.99-6.79) * *$ \\
\hline No & $67(23.7 \%)$ & $216(76.3 \%)$ & 1.000 & & & \\
\hline \multicolumn{7}{|c|}{ Physical activities } \\
\hline Yes & $22(25.9 \%)$ & $63(74.1 \%)$ & 1.000 & & & \\
\hline No & $271(56.2 \%)$ & $211(43.8 \%)$ & $\begin{array}{l}3.678(2.192- \\
6.172)\end{array}$ & $\begin{array}{l}< \\
0.001 *\end{array}$ & $0.003^{* *}$ & $3.20(1.50-6.81) * *$ \\
\hline
\end{tabular}


$\mathrm{NB}$ : $\mathrm{COR}=$ crude odds ratio, $\mathrm{AOR}=$ adjusted odds ratio, $*=$ significant association (on bivariate), $* *=$ significant association (on multivariate), $1.000=$ Reference.

\section{Figures}

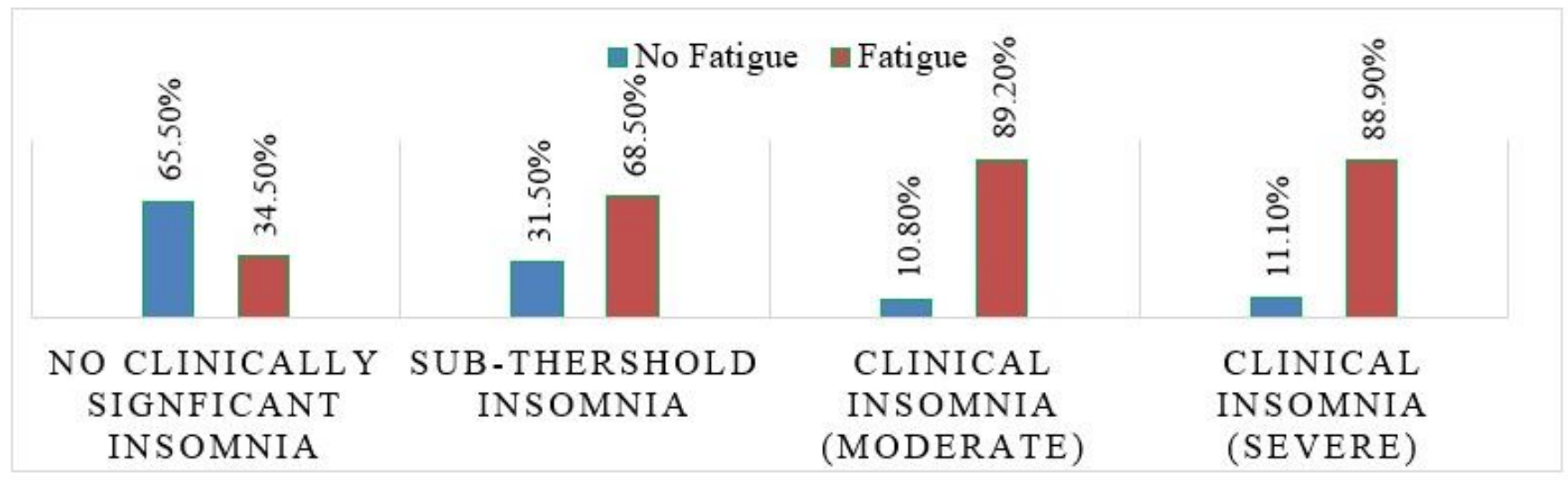

\section{Figure 1}

The proportion of fatigue among people living with HIV/AIDS, with different insomnia level, attending ART, in Mekelle city public and private health facilities, North Ethiopia, April 2019, $(n=567)$.

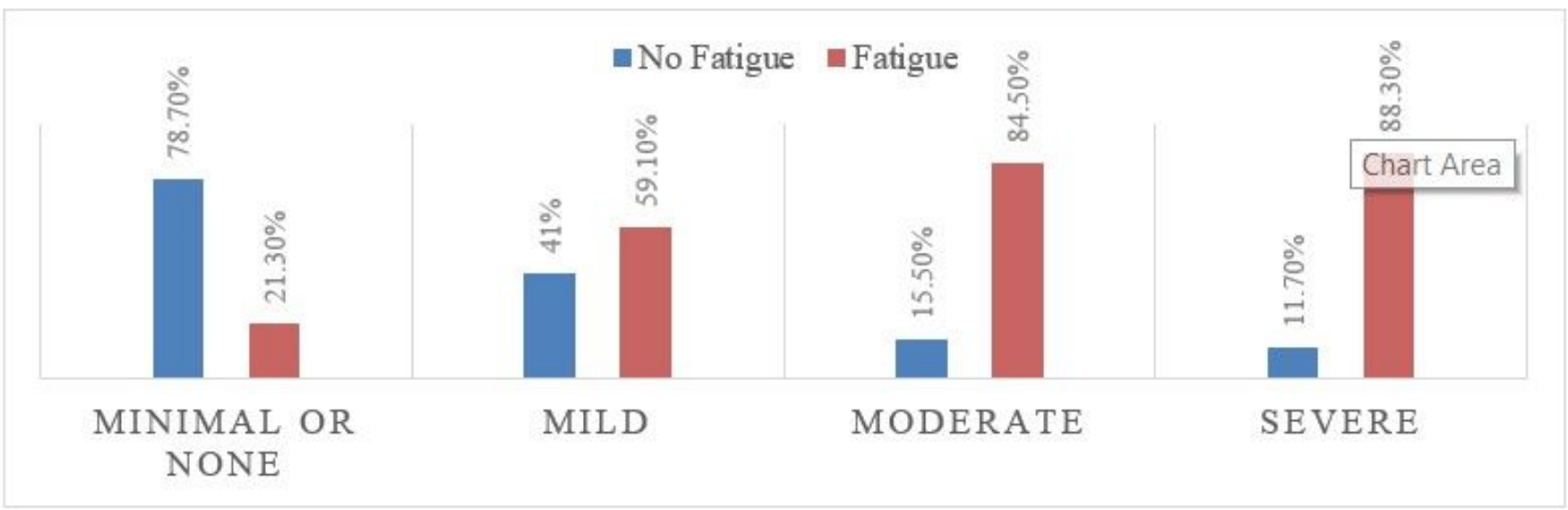

\section{Figure 2}

The proportion of fatigue among adults living with HIV/AIDS, with different depression level, attending ART, in Mekelle city public and private health facilities, North Ethiopia, April 2019, $(n=567)$. 